\title{
Culpa e Vergonha na Constituição da Subjetividade: Ensaio de Psicanálise Aplicada Sobre o Filme "Shame"
}

\section{Guilt and shame on subjectivity constitution: an applied psycho-analysis essay about the movie "Shame"}

\section{Culpa y vergüenza en la constitución de la subjetividad: Ensayo de psicoanálisis aplicada sobre la película "La vergüenza"}

\section{Maysa Maria Napolitano Machado*}

Universidade Estadual Paulista "Júlio de Mesquita Filho" - UNESP, Bauru, São Paulo, Brasil

\section{Victória de Freitas Branco**}

Universidade Estadual Paulista "Júlio de Mesquita Filho" - UNESP, Bauru, São Paulo, Brasil

\section{Maíra Bittar Galdi***}

Universidade Estadual Paulista "Júlio de Mesquita Filho" - UNESP, Bauru, São Paulo, Brasil

\section{Érico Bruno Viana Campos****}

Universidade Estadual Paulista "Júlio de Mesquita Filho" - UNESP, Bauru, São Paulo, Brasil

\section{RESUMO}

Este artigo consiste em um ensaio de psicanálise aplicada sobre o filme "Vergonha" (Shame). A interpretação está focada sobre a relação entre os dois personagens principais, com destaque para o protagonista, Brandon. A análise do filme apresenta a angústia depressiva e a impossibilidade de elaboração do luto pela perda do objeto como elementos centrais da subjetividade narcísica. O objetivo é discutir questões mais amplas com relação à caracterização das formas próprias de sofrimento nos modos de subjetivação contemporâneos, em que a relação com as instâncias ideais caracteriza-se muito mais pela mediação do ideal de ego narcísico, cujo teor afetivo é da ordem da vergonha, do que do superego edípico, cujo teor afetivo é da ordem da culpa.

Palavras-chave: psicanálise, cinema, mal-estar, narcisismo.

\section{ABSTRACT}

This article is an applied psychoanalysis essay about the movie "Shame". The interpretation focus the relationship between the two main characters, 
specially the protagonist, Brandon. The film analysis presents the depressive anguish and the impossibility of working through mourning the loss of object as central elements of the narcissist subject. It aims to discuss broader issues regarding the suffering in contemporary subjectivity, in which the relationship with the ideals are characterized more by the mediation of the narcissistic ideal of ego, whose emotional content tends to shame, than the oedipal superego, whose emotional content tends to guilt. Because of this, it shows that the film's title is quite appropriate to the psycho-dynamic issues that arise in its plot and also illustrative of depressive anxiety and existential emptiness that underlie the malaise in the culture of narcissism nowadays.

Keywords: psychoanalysis, motion, movie, narcissism.

\section{RESUMEN}

Este artículo es un ensayo del psicoanálisis aplicada sobre la película "Shame". La interpretación se centra en la relación entre los dos personajes principales, especialmente el protagonista, Brandon. El análisis de la película muestra la ansiedad depresiva y la imposibilidad de elaboración del duelo por la pérdida del objeto como elementos centrales de la subjetividad narcisista. El objetivo es discutir cuestiones más amplias relativas a la identificación de las formas de sufrimiento en los modos de subjetivación contemporáneos, en la que la relación con los ideales se caracterizan más por la mediación del ideal narcisista del ego, cuyo contenido emocional tiende a la vergüenza, que el superyó edípica, cuyo contenido emocional tiende a la culpa. Debido a esto, se demuestra que el título de la película es bastante adecuada a las cuestiones psicodinámica que surgen en su trama y también ilustrativo de la ansiedad depresiva y el vacío existencial que subyacen en el malestar en la cultura del narcisismo en la actualidad.

Palabras clave: psicoanálisis, malestar, cinema, narcisismo.

\section{Introdução}

Este artigo apresenta e discute uma das expressões mais frequentes do mal-estar na contemporaneidade, qual seja, uma busca insaciável por objetos que apaziguem a angústia por meio de satisfações corporais imediatas. Trata-se de um exercício de psicanálise aplicada sobre o filme "Shame" (Vergonha), de Steve McQueen (2011), focado na relação entre seus dois personagens principais, com destaque para o protagonista Brandon.

Atualmente, as características mais emergentes das relações amorosas baseiam-se em uma flexibilização dos laços, que passam a ser mais esporádicos e muitas vezes dispensam a necessidade de um compromisso. Paralelamente, observa-se também uma crescente carência por contatos mais profundos, mas paradoxalmente, na mesma intensidade com que são desejados, também são temidos, pela ameaça que estes representam para a liberdade individual conquistada historicamente e tão valorizada até então. Trata-se de um contexto de aprofundamento das rotinas e referências da subjetividade moderna ocidental, centrada na consciência reflexiva, na intimidade afetiva e no individualismo social. A subjetividade 
própria da atualidade tem características de um autocentramento e individualismo exteriorizado, voltado para ideais performáticos e narcísicos em que o registro da imediatez dos prazeres corporais ganha destaque (Birman, 2001).

Nesse contexto em que o narcisismo é o modelo principal das relações interpessoais, o sexo está sendo visto muito mais como uma das vias para a auto descarga de tensões acumuladas, tendo seu significado esvaziado. Na contemporaneidade ela se caracteriza por um ato mais solitário, mesmo que praticado em grupo, centrado no próprio prazer. Desse modo, as relações amorosas e sexuais encontram-se agora sob o império da imagem:

Nas relações interpessoais, a possibilidade de dialogar cede espaço à imagem, e a palavra perde relevância como suporte do pensamento e da subjetividade, e também como suporte da intersubjetividade e do vínculo. Fala-se em um neonarcisismo próprio desta época, que instaura um culto pelos corpos cuidados e uniformizados num mesmo padrão de beleza. Há prevalência da aparência, em detrimento de qualquer profundidade. Talvez haja, também, mais intercâmbio de imagens que de pensamentos, emoções e palavras (Fuks, 2003, p. 25-26).

É dessa forma que o termo amor líquido, criado pelo sociólogo Bauman (2009), caracteriza tão bem essa nova forma frágil de se relacionar, que se baseia muito mais na quantificação de relações, onde impera a lógica do consumo/descarte, assim como o são as relações de mercado. Dessa forma, a lógica que marca a contemporaneidade não é mais a lógica do "querer ser", mas sim do "querer ter" o objeto, para ser o objeto através do qual o outro goza. Nesse contexto, as compulsões sexuais e o comportamento autodestrutivo são algumas características que se expressam nos relacionamentos da contemporaneidade que, muitas vezes, se tornam vias privilegiadas de expressão do sofrimento das pessoas.

O filme "Vergonha" (Shame) foi escolhido por retratar bem essa problemática do homem contemporâneo, demonstrando o tipo de sofrimento vivido pelo personagem Brandon (Michael Fassbender) e sua irmã Sissy (Carey Mulligan). O filme é uma produção inglesa de 2011, dirigido pelo cineasta Steve McQueen (2011). Suas opções estéticas assépticas e minimalistas que mimetizam a conduta do personagem principal, com um roteiro, dele próprio e de Abi Morgan, que não se preocupa em apresentar uma narrativa linear e explícita, que foram apontadas como pontos fortes do filme (Argentieri, 2012). Trata-se, este artigo, de um ensaio teórico, baseado em uma metodologia de psicanálise aplicada, em que o método e as categorias conceituais da psicanálise são utilizados como recurso para 
interpretação de fenômenos culturais (Rosa, 2004; Kobori, 2013), neste caso, uma obra cinematográfica. O uso do filme é feito no sentido de que seu enredo traz uma série de indicações pertinentes e ilustrativas para discussão e reflexão sobre as características dos modos de subjetivação da contemporaneidade, de forma tal que consiste um motivador para uma discussão mais ampla, que não se apoia exclusivamente sobre os elementos trazidos pela obra. Nesse sentido, a proposta não é fazer uma psicobiografia do autor ou uma construção hipotética e especulativa sobre os personagens como exemplos de personalidades reais, nem mesmo promover uma análise exaustiva da experiência estética do filme como obra de arte, mas apenas, de forma mais ensaística e assistemática, trabalhar seus elementos mais ilustrativos para substanciar uma reflexão teóricoconceitual no campo psicanalítico.

\section{Um percurso pela narrativa cinematográfica}

Brandon é um homem na faixa dos trinta anos de idade, bemsucedido, bonito, que mantém um emprego como publicitário na almejada cidade de Nova York. Embora aparente uma vida confortável e de sucesso, apresenta dificuldades em fazer e manter vínculos com as pessoas - tem poucos amigos, não tem parceira amorosa fixa e mantém uma relação ambígua com sua irmã. Diante de uma vida marcada por relações lábeis e por um distanciamento afetivo das pessoas, ele passa boa parte do seu tempo buscando ou engajado em atividades sexuais, configurando uma compulsão que não consegue controlar.

As cenas iniciais do filme retratam a fugacidade e impulsividade nas relações afetivas de Brandon, que se mostra buscando mulheres em bares e na rua ou contratando serviços de profissionais do sexo. Em uma dessas cenas, Brandon está no vagão de metrô quando nota uma mulher se interessando por ele. A troca de olhares e a expressão corporal da sedução toma lugar com a mulher se insinuando discretamente e ele se mostrando impassível. Brandon se aproxima dela e a segue na saída do metrô para tentar uma investida sexual, mas ela se perde na multidão, deixando-o frustrado. Há um corte e a narrativa prossegue, como se se tratasse de mais um encontro fortuito em que a impulsividade sexual emerge para logo se desmobilizar.

Esse clima inicial de caracterização da rotina do personagem é logo perturbado por ligações de telefone de uma mulher que insiste em falar com ele. $O$ espectador demora um pouco para entender que se trata de sua irmã, que acaba por vir ao seu apartamento e se instalar nele. Este fato marca uma ruptura no cotidiano de Brandon, 
instaurando uma progressiva crise que será demonstrada ao longo do filme.

É notório que o personagem central da trama deseja se desvencilhar de seu passado, porém os motivos desse afastamento permanecem um mistério do começo ao fim. Com relação a isso, a única frase proferida durante o filme é pela sua irmã Sissy, que murmura, aos prantos: "Nós não somos pessoas más. Nós apenas viemos de um lugar ruim". Apesar desse possível passado doloroso, o personagem consegue alcançar seus ideais de vida e estabelecer uma rotina, 0 que o deixa em um estado de estabilidade física e psíquica. Porém, esse equilíbrio é alcançado às custas de sua vida interior, pois além de suprimir seus afetos, também evita todo e qualquer tipo de vínculo emocional, estabelecendo para si um estilo de vida totalmente pragmático e cru. Isso é refletido em todos os aspectos de sua aparência física e de seu próprio apartamento, que se apresenta em cores sóbrias, intacto, desprovido de marcas pessoais. A rotina cristalizada foi o modo como Brandon conseguiu se arranjar para viver. Entretanto, quando a monotonia se torna insuportável, sai em busca de aventuras sexuais rápidas, sem afeto e sem compromisso, com parceiras eventuais. A presença do sexo é uma constante em sua vida, que ocupa não somente suas horas livres, mas também seu ambiente de trabalho, fazendo-o passar por situações constrangedoras.

Uma mudança substancial em sua vida ocorre com a chegada de sua irmã Sissy, que surge sem aviso prévio para ficar em seu apartamento. Em contraste com Brandon, Sissy é impulsiva, passional, frágil e com tendências autodestrutivas. Sua passividade é materializada até mesmo em sua aparência: loura de pele leitosa quase transparente, ela se assemelha a uma criança. Sempre dependendo de alguém para sobreviver - tanto financeiramente como emocionalmente - ela busca apoio em seu irmão, após mais um relacionamento fracassado.

As dificuldades no relacionamento com sua irmã, que são os precipitantes da crise de Brandon e também o mote do filme, são uma tendência que se estende para todo campo relacional do protagonista e talvez sua marca mais característica. Podemos pensar que esse sintoma expresse uma forma de proteção diante do medo que sente pela possibilidade do estabelecimento de um relacionamento, dada a sua angústia de um dia poder vir a perder o objeto amado. Isso pode ser muito bem observado na evitação que Brandon exerce sobre qualquer proximidade física com sua irmã e a impossibilidade de manter relações sexuais com uma colega de trabalho a qual tentou estabelecer um vínculo que fosse além do sexo. A questão que essas duas situações suscitam é sobre a natureza do conflito fundamental em jogo na relação de Brandon com as mulheres. A princípio, podemos pensar em uma cisão entre a 
mulher para ter relações sexuais, objeto e sujeito de uma sexualidade vil e suja, e a mulher amada, idealizada e assexuada. Sissy, a colega de trabalho e a mulher do metrô estariam nesse lugar protegido e qualquer aproximação e possibilidade de contato dessas figuras com as mulheres "objeto" traria angústia e, principalmente, culpa moral. Essa poderia ser a explicação para condutas de evitação e tentativas de isolamento, tais como os rituais de limpeza ou o episódio em que joga todo o seu material pornográfico no lixo. A história mostra uma progressiva perturbação desse arranjo de cisões e isolamentos, motivada pelas demandas da irmã. Isso faz com que ele entre em uma espiral de movimentos impulsivos e desafiadores, chegando ao ponto do descontrole e a passagens ao ato.

Uma sequência de cenas já no final da história representa o ápice da crise de Brandon. Nela, ele seduz uma mulher em um bar, às vistas de seu companheiro, em um claro desafio de rivalidade masculina. Mas sua posição assertiva incisiva diante da mulher contrasta com a passividade com que se deixa apanhar do homem. Na sequência ele se dirige ferido para uma boate própria para relações sexuais entre homens e lá se engaja em uma relação homossexual em que ele fica na posição ativa enquanto outro homem lhe faz sexo oral, indicando por esse ato a possibilidade de satisfação de uma fantasia de triunfo por submeter o rival a sua potência fálica. Depois desse triunfo sobre a figura masculina, ele se dirige para o apartamento de duas mulheres e se engaja em um sexo a três bastante intenso. O que chama a atenção nessa cena é a crueza e intensidade do prazer no intercurso sexual, ilustrando uma poética ambivalência entre dor e satisfação no gozo sexual.

A ambivalência emocional intrínseca desse percurso do protagonista é potencializada pela narrativa paralela, em que Sissy, cansada da frustração de sua demanda pelo apoio do irmão e desenganada pelo envolvimento com o amigo e chefe deste comete uma tentativa de suicídio. No que diz respeito a ela, a dinâmica também ilustra uma saída feminina típica: a mulher que se identifica inconscientemente com o objeto sexual sujo e indigno, buscando relações amorosas em que a rivalidade e o limite ao desejo são centrais. O chefe de Brandon é casado e claramente só buscava uma aventura sexual. Ele está no lugar de um objeto interditado, por ser de outra mulher e por representar por deslocamento o irmão, além de representar bem o papel de homem "canalha". Sissy é seduzida por essa armadilha de seu desejo e depois se coloca na mesma posição de dependência e demanda insistente que se vê com seu irmão, mostrando que esta é a tônica de seus relacionamentos com os homens. Sua tentativa de suicídio parece ser uma passagem ao ato em que a identificação com a posição de coitada se expressa na forma de um sadismo autodirigido que chega ao limite da vida. 
Enquanto Brandon parece apresentar uma saída maníaca, em constante atividade, Sissy é, em contrapartida, muito melancólica e passiva durante a maior parte do tempo. Sendo assim, percebe-se a contradição: Brandon, em uma imagem inabalável, forte e inatingível e Sissy, extremamente frágil. Mas, por outro lado, este contraste sugere também uma complementaridade em que uma mesma problemática de fundo subsiste de forma compartilhada. Desde o primeiro momento, Sissy se mostra muito invasiva na vida de seu irmão. Na primeira cena em que ela aparece, o espectador se confunde com o papel que ela pode desempenhar na vida dele: esposa, irmã, namorada ou amante? Isso por que, além das ligações por telefone apelativas, ela invade seu apartamento e sua intimidade ao entrar sem avisar, mexendo em suas coisas sem maiores constrangimentos. A relação entre os dois se mostra com limites muito tênues: em alguns momentos são muito próximos um do outro, chegando a se fundir, dado o grau de dependência estabelecido de um lado, pela irmã, que tem que se apoiar financeiramente e emocionalmente em alguém, e de outro, Brandon, que não consegue estabelecer outro laço íntimo em sua vida que não seja com ela. Nesse contexto de frequentes desentendimentos por um embate de contrários, Brandon direciona-se para uma abordagem na qual ignora a irmã, fingindo sua inexistência, enquanto Sissy implora para ser aceita novamente. Essas duas posições, que oscilam do extremo da dependência para o extremo da indiferença, provocam muito sofrimento em ambos. Essa qualidade afetiva, que se expressa hora no sentimento de vazio, hora na demanda sufocante, também é uma característica pertinente.

Uma das cenas mais relevantes nesse sentido seria o momento no qual Sissy apresenta-se em um bar cantando a música New York, New York com uma tônica bastante melancólica, o que é algo destoante do ritmo e da letra da música que transparecem alegria e triunfo de vencer em uma cidade que representa um ideal para o mundo. O que chama a atenção no filme é que ela é cantada por Sissy de uma forma extremamente triste e frágil, atestando muito mais o fracasso dessa ilusão fantasiosa do que sua realização, reiterando sua tendência passiva e depressiva. É um momento bastante dramático e no qual aparece, pela primeira vez, uma ruptura da imagem inabalável de Brandon. Ele se emociona a ponto de discretamente verter lágrimas de seus olhos, mas a expressão do choro é inibida e qualquer reconhecimento de fragilidade, negado. Esse pequeno lapso emocional é suficiente para se pensar que houve entre eles o compartilhamento de uma fantasia de recomeçar a vida nessa nova cidade como uma forma de reparar e superar o mal vivido por ambos no passado. Infelizmente o filme não nos permite avançar na natureza específica desse trauma. Também não permite avançar muito na interpretação de fantasias ou mecanismos, mas permite ao 
menos afirmar que é algo da ordem de um sofrimento melancólico, de perda de um objeto primário de amor. Então, parece que os irmãos compartilharam essa saída em certo pacto de superação da dependência e da impotência, mas o fizeram de formas muito distintas, embora complementares.

A cena da apresentação de Sissy é também o momento que marca o envolvimento dela com o chefe de Brandon, ocasião do filme em que é possível constatar a falta de limites na relação entre os irmãos. Após a apresentação no bar, os três pegam um táxi em direção ao apartamento de Brandon. Os dois, que já estão envolvidos, comportam-se como se Brandon não existisse, entrando em seu apartamento e mantendo relações sexuais em sua cama. A angústia da personagem é tanta que ele pensa em começar a se masturbar, mas diante da ideia de fazê-lo frente a uma relação sexual da própria irmã, ele sai de casa, fazendo uma corrida pelas ruas, buscando aplacar um pouco a excitação. Essa saída em ato por meio de uma descarga corporal ilustra um mecanismo característico do personagem, que, diante de qualquer angústia, é impossibilitado de pensá-las ou busca abrandar seus pensamentos através, principalmente, da atividade sexual.

A partir dessa luta diária contra demonstrar para si e para os outros seus sentimentos e mundo interno, a vida de Brandon torna-se sufocante. Em consonância, o cenário cinematográfico coaduna com a personalidade do personagem principal: o filme é repleto de prédios extremamente lacrados, mas, em contraposição a isso, suas fachadas envidraçadas são completamente transparentes. Os vidros, além de serem frágeis, deixam seu mundo interno acessível aos olhos do público, mas também extremamente distante dada as barreiras físicas que separam as pessoas da presença de sua intimidade. Mas a angustiante questão está na dificuldade de discernir em Brandon um traço de originalidade. Ele, que é todo construído a partir desses ideais com os quais se identificou fortemente, carece de gostos pessoais. Sendo assim, à maneira como os prédios mostram para o público sua intimidade, Brandon também se exibe nas relações sexuais que mantém, como se apenas aquilo o fizesse sentir-se vivo, o que parece apontar, para além do puro fetiche do exibicionismo, uma angústia de ordem mais narcísica. Embora toda noite esteja na companhia de um novo corpo, suas relações afetivas íntimas são praticamente nulas.

Quando Brandon encontra sua irmã ensanguentada no banheiro, mas não morta, ele chora, destravando seu embotamento emocional. Este é propriamente o momento de desfecho da narrativa do filme, na descarga angustiada de um choro e de uma dor inibidas. Contudo, 0 filme é encerrado em uma cena com as características de um epílogo que se segue ao momento de queda e fragilidade do personagem principal: Brandon aparece novamente no metrô e reencontra a 
mulher do início. Ela está novamente sentada e com expressão corporal de quem se engaja em um jogo de sedução. A cena é claramente uma repetição do mesmo momento chave do começo do filme. Ela se levanta e ele se aproxima por trás, pousando sua mão perto da dela. A câmera fecha em suas mãos e na iminência do toque, mas o filme termina aí, nesse momento em suspenso. Uma circularidade na narrativa é estabelecida e um descolamento da repetição é aventado. Talvez se anuncie uma nova saída, em que o homem e a mulher possam encontrar-se e se relacionar de forma mais harmônica e complementar. Contudo, ele não termina com uma redenção ou elaboração do conflito, pelo contrário, permanece tenso e em suspenso, o que caracteriza mais uma indicação de sua atualidade.

\section{O sofrimento narcísico e a vergonha}

Uma característica do roteiro e montagem do filme é se ater à trama presente e a diálogos carentes de aprofundamento subjetivo e de intimidade, o que dificulta a interpretação da motivação consciente e inconsciente dos personagens. Essa opção é interessante por ressaltar o caráter externalizado e concreto da subjetividade contemporânea, mas deixa o intérprete frustrado em busca de uma explicação psicológica que remeta à história de vida anterior dos personagens. Apesar da escassez de referências biográficas e de diálogos mais substanciais em termos de expressão dos estados psíquicos e emocionais dos personagens, entendemos que a dinâmica das condutas e mesmo as passagens ao ato que se efetivam durante o filme são suficientemente ilustrativas das características gerais que estão presentes nos modos de subjetivação da atualidade, permitindo derivar elementos para discussão sobre certas dinâmicas narcísicas em que a relação com a angústia pela perda do objeto e a relação com os componentes ideais do ego são centrais. Nossa interpretação incidirá sobre alguns elementos dessa relação fraternal e principalmente do protagonista para problematizar o lugar do afeto de vergonha na economia psíquica do narcisismo contemporâneo.

Interpretações psicanalíticas do filme ressaltam as características de um esvaziamento da dinâmica introspectiva, regressões ao funcionamento corporal e a passagens ao ato como aspectos centrais de seu protagonista:

Desse modo, em um estilo muito atual, o caso clínico de Brandon carece de história, profundidade emotiva e dimensão inconsciente. As complicações sentimentais e morais ficam fora de cena e tudo se reduz ao comportamento, a concretude regressiva do funcionamento corporal. A relação, ainda que 
patológica, não é com as mulheres, mas com seu pênis, que, somente quando está ereto o faz sentir-se vivo, e apenas o orgasmo the permite anular-se brevemente e vencer o malestar que o domina. O efêmero simulacro de identidade, porém, não constrói nada dentro dele e o condena à monótona repetição da experiência. Mais do mesmo, sem criatividade. Há um vazio de sentido que permeia a trama, provocando nos espectadores uma nesga de angústia, mais próxima da repugnância que do escândalo (Argentieri, 2012, s/p).

O filme mostra algumas passagens ao ato centrais e em geral os atos têm um papel de destaque na conduta dos personagens. A psicanálise definiu alguns conceitos para descrever a dinâmica dos atos. Muito da discussão sobre esses conceitos incide sobre o manejo técnico do processo analítico e as relações com a dinâmica da transferência, mas o que interessa destacar é a noção geral de ato que a psicanálise concebe. A atuação consiste em um processo por meio do qual as fantasias e desejos inconscientes são vividos no presente com um sentimento de atualidade e de forma compulsiva. Tem, nesse sentido, um caráter de atualização do conteúdo representacional das fantasias na forma de atos e de afetos que tendem à descarga por meio do corpo, que em vez de serem lembrados e pensados, são vividos em ato. A oposição entre recordar e atuar é um ponto central na lógica dos processos de elaboração psíquica, como pode ser atestado nos textos técnicos de Freud (1996a). As atuações podem ser de diferentes formas e em diferentes contextos, sendo sua caracterização mais drástica descrita como acting out ou passagem ao ato, que se destacam por serem "ações que apresentam, quase sempre, um caráter impulsivo, relativamente em ruptura com os sistemas de motivação habituais do sujeito, relativamente isolável no decurso de suas atividades, e que toma muitas vezes uma forma auto ou hetero-agressiva" (Laplanche e Pontalis, 1998, p. 6). Assim, pode-se afirmar que as passagens ao ato, expressam as formas mais radicais de falha nos caminhos habituais de simbolização e pensamento do aparelho psíquico, em que o ego é tomado por um impulso para a ação que toma o lugar da elaboração psíquica e dos processos de pensamento reflexivo.

Muitas vezes tende a se tomar as passagens ao ato como indicativas de condutas transgressivas, em oposição ao de pensamento reflexivo como norma dos processos de subjetivação. Contudo, essa postura expressa uma concepção caracteristicamente moderna de compreensão dos fenômenos psicológicos em que a mente é definida como essencialmente organizada por processos de representacionais de caráter ideativo e verbal como ideais de regulação do pensamento, que devem suplantar os impulsos afetivos que tendem a se expressar no corpo e na forma de atos, ou seja, a noção que o 
ideal de subjetivação e produzir simbolizações da ordem do pensamento em lugar de expressões corporais compulsivas e involuntárias. Isso fez com que em psicanálise se priorizasse 0 registro do pensamento como o caminho para elaboração da repetição compulsiva dos impulsos afetivos que tendem a se expressar em atos irrefletidos e involuntários, tal como pode ser notado na noção fundamental de que a elaboração é o que permite a recordação no plano do pensamento daquilo que tende a se repetir na forma de uma atuação compulsiva (Freud,1996a). Nesse sentido, o registro das intensidades afetivas, dos atos e do corpo, tende a ser minorado em detrimento do pensamento simbólico, reflexivo e interiorizado. Contudo, no contexto da cultura contemporânea, o que se observa é justamente o privilégio dessas vias na constituição dos modos de subjetivação que se tornam os meios preponderantes de modulação pulsional e também de expressão do sofrimento. Birman, ao propor uma cartografia do mal-estar na atualidade, enfatiza essa transformação:

Dessa maneira, o mal-estar na atualidade enuncia-se positivamente nos registros do corpo, da ação e do sentimento. Estariam aqui as categorias antropológicas que fundam as descrições da subjetividade contemporânea, delineando as novas formas de subjetivação. Estas são as invariantes em questão. (...) A positividade dessas categorias nesses discursos, no entanto, evidencia a negatividade de outras. 0 que se destaca aqui é a ausência e a fragilidade da categoria de pensamento nas descrições das novas formas de subjetivação. Disso deriva a fragilidade dos processos de simbolização e o empobrecimento da linguagem e do discurso nas subjetividades atuais, ao lado da pregnância assumida pela categoria do espaço em detrimento da categoria de tempo nos processos psíquicos (2006, p. 213).

Esse tipo de transformação traz uma série de questões para a compreensão psicanalítica da subjetividade na contemporaneidade, em especial porque evidencia o limite de se pensar exclusivamente ou relacionar diretamente os fenômenos de passagem ao ato ao registro das perversões a partir do modelo do fetichismo sexual (Freud, 1996e). Assim, nessa perspectiva, pode-se entender que os fenômenos de atuação compulsiva, tão bem ilustrados no filme, não caracterizam necessariamente uma negatividade ou perversão em relação a uma normatividade neurótica regulada pela castração e pela simbolização. Além disso, para além de qualquer preocupação nosográfica ou psicopatológica, entendemos que a riqueza do filme está em apontar para além da caracterização do sintoma como da ordem do ato, do corpo e da transgressão, mas em como ele 
expressa justamente essa falha dos processos de simbolização da ordem do pensamento e da linguagem.

Uma interpretação semelhante das condutas compulsivas sexuais tematizadas na contemporaneidade pode ser encontrada na análise que Birman (2012) faz do filme "De Olhos bem Fechados", de Stanley Kubrick, cuja personagem principal e o enredo apresenta muitas características em comum com o filme que estamos analisando. $O$ autor destaca a concretude das passagens ao ato e a impossibilidade de sonhar e desejar como forma privilegiada de expressão das fantasias, evidenciando não só a preponderância dos registros do espaço, do corpo e da ação, mas a impossibilidade de um sofrimento compartilhado e alteritário, de forma tal que o registro dos sentimentos é da ordem da dor e da solidão. Nesse sentido, o que filmes como esse ilustram é a perseguição do desejo no campo da realidade, em detrimento da simbolização, indicando o que o autor intitula de deserto do real.

Entendemos também, acompanhando a literatura que nos apoia (Birman, 2001, 2006, 2012; Campos, 2013; Costa, 2005, 2012; Delouya, 2001; Fuks, 2003, 2010;), que o registro fundamental para compreender essa dinâmica da subjetivação contemporânea seja o do narcisismo e que o filme também ilustra aspectos pertinentes a essa discussão teórica, em especial porque sinaliza para a qualificação da dinâmica afetiva em jogo, que é onde acreditamos residir a contribuição específica de nossa análise.

Para a Psicanálise, o narcisismo não é apenas uma patologia, mas sim, um fenômeno constituinte e estrutural do psiquismo, no qual o sujeito começa por tomar a si mesmo, ao seu próprio corpo, como objeto de amor (Freud, 1996b). Na perspectiva freudiana clássica, entende-se que no narcisismo primário há um investimento da libido no ego para a sua constituição, enquanto no secundário há um retorno regressivo ao ego da libido dos investimentos objetais (Laplanche e Pontalis, 1998). A forma de elaboração do narcisismo primário e o encaminhamento de sua problemática no desenvolvimento do aparelho psíquico pode levar à constituição de vínculos objetais preponderantemente de caráter narcísico ou anaclítico (Freud, 1996b). Um encaminhamento importante dessa concepção de relação de objeto narcísica deu-se na interpretação dos fenômenos melancólicos a partir do contraponto com o processo de luto, em que Freud (1996c) caracterizou a melancolia como expressão de um mecanismo de identificação com o objeto perdido, causando uma série de ataques sádicos inconscientes ao ego que se expressam na forma de auto-recriminações e sentimentos depressivos. Nessas condições, se percebe uma depressão profunda, caracterizada por uma perda de interesse pelo exterior e por um desinvestimento psíquico geral em que o sujeito é tomado por extrema dor psíquica, podendo levar a uma reversão maníaca com 
sintomas delirantes e passagens ao ato. Posteriormente, em uma última organização em sua categorização psicopatológica, o autor afirma que o conflito fundamental que rege a dinâmica das neuroses narcísicas, onde se enquadrariam as melancolias, seria entre o ego e o superego, em oposição aos conflitos ego e realidade, característico das psicoses, e ego e id, característico das neuroses (Freud, 1996d). Apesar dessas indicações, a teoria do narcisismo precisou de uma série de aportes das escolas pós-freudianas para avançar na circunscrição e caracterização dessas dinâmicas na constituição do aparelho psíquico. Na tradição lacaniana, a grande contribuição veio no sentido de pensar o narcisismo em dois momentos, articulados à função materna e ao registro do imaginário, prévios ao complexo de Édipo propriamente dito, articulado à função paterna e ao registro do simbólico (Dor, 1991). O modelo para pensar o narcisismo é o da alienação imaginária na constituição da função do eu por meio do estádio do espelho, em que a unidade egoica do bebê se organiza a partir da identificação com os significantes imaginários veiculados pela função materna, de forma que o bebê assume a posição de ser o falo materno (Lacan, 1998). Essa posição narcísica, por sua vez, se articula em dois níveis, um narcisismo primário, em que a função egoica e a função materna são ainda indiferenciadas, de forma que o ego coincide com o próprio ideal, e um narcisismo secundário, em que a posição do ego atual não coincide com o ideal, mas é mediada por uma significação imaginária do desejo materno que se constitui como uma instância, o ideal do ego (Lacan, 1986).

Já na tradição das relações de objeto, as contribuições kleinianas sobre os estágios pré-genitais da libido lançaram luz sobre os modos primitivos de relação com os objetos e, portanto, sobre as dinâmicas narcísicas, a partir das concepções de posição esquizoparanoide e de posição depressiva, como dois momentos estruturantes da personalidade. Nessa concepção, tem-se duas constelações de fantasias, angústias e defesas, que se articulam em uma sucessão lógica, porém não necessariamente em um desenvolvimento linear e cronológico, passando de um estado de cisão e projeção de objetos parciais gerando angústias de fragmentação e perseguição (Klein, 1991), para um estado de integração do seio bom e do seio mau em um objeto total por meio da elaboração da angústia depressiva pela destruição do objeto materna em função de mecanismos de reparação que constituem o fundamento para a possibilidade de simbolização efetiva e clara distinção entre o ego e a realidade (Klein, 1996). A matriz clínica de onde partem as considerações kleinianas sobre a posição depressiva é a da melancolia em sua articulação com episódios maníacos, mostrando um encaminhamento da problemática melancólica e da identificação narcísica inicialmente estabelecida por Freud (1996c), ressaltando a angústia pela perda do objeto primário de amor como fator afetivo mobilizador das defesas e trazendo a 
caracterização das defesas maníacas como uma forma de negação da experiência de perda e de luto (Campos, 2013).

Apesar das diferenças significativas na abordagem da temática do narcisismo por essas duas tradições, ambas ressaltam os aspectos sádicos e destrutivos como elementos organizadores da relação constituinte do ego com o objeto materno primário (Campos, 2013). Nesse sentido, também é possível pensar a convergência dessas concepções em torno da noção de uma afetividade depressiva primária, como eixo importante de constituição da diferenciação entre sujeito e objeto e, portanto, de elaboração das dinâmicas narcísicas:

A depressão eclode, segundo essa concepção, com a consciência de ser separado da mãe ou com a perda progressiva dela, na esteira do nascimento do sujeito - do eu -, e o consequente reinvestimento de si. É o momento capital que figura na posição depressiva de Melanie Klein, no estádio do espelho do Lacan, no estado de preocupação de Winnicott e na fase de separação/individuação de Mahler. (...) O sentimento de ter perdido o objeto ou aspectos dele, e a resignação diante desta perda, à medida que a criança não é capaz de restaurar o objeto dentro de si, marca o nascimento do afeto depressivo, assim como o da instalação da sensibilidade depressiva. (...) 0 afeto depressivo situa-se, então, nesse ponto central de transição, constitutivo do psiquismo, em que a abdicação narcísica, da onipotência e da fusão, se faz necessária (Delouya, 2001, p. 33).

Além disso, autores no contexto da psicanálise contemporânea têm tentado articular os aportes das diferentes tradições pós-freudianas para pensar as demandas dos modos de subjetivação na contemporaneidade. Nesse contexto, um grande destaque se dá à proposta de Green (1988) de pensar, a partir da noção de um narcisismo de morte, a necessidade de pensar o lugar do trabalho do negativo na constituição e elaboração das dinâmicas da subjetividade. O narcisismo negativo ou de morte diz respeito às dinâmicas narcísicas reativas, de desinvestimento objetal, próprias de estados de defusão libidinal em que opera preponderantemente a pulsão de morte por conta de falhas no suporte do objeto materno na constituição primária das identificações narcísicas. Ele é marcado por uma qualidade afetiva de neutralidade e esvaziamento subjetivo, portanto, de caráter negativo, em contraposição à positividade da angústia pela perda do objeto própria dos estados de luto e melancólicos, mas ele deve ser entendido como uma desorganização regressiva dos vínculos libidinais na forma de inibição dos investimentos objetais como forma de proteção. Portanto, tratam-se de dinâmicas ainda mais arcaicas dos impulsos sádicos próprios da 
pulsão de morte, mas ainda assim da seara de um eixo narcísico e melancólico da subjetividade.

Muitas dessas proposições se deram a partir da discussão sobre os chamados estados limítrofes ou quadros borderlines em psicanálise, em que, além de André Green, se destacam também os trabalhos de Kernberg (1996) e Bergeret $(1974,2006)$. Este último, em sua proposta de um modelo geral de organização da psicopatologia psicanalítica, caracteriza o espectro das organizações limítrofes de personalidade a partir da tônica na problemática narcísica. Nesses quadros, a formação do superego não se dá como na neurose clássica, na qual ele é elemento estruturante a partir da identificação com os ideais paternos e simbólicos. Ao invés disso, observa-se um superego gigantesco, onde predomina o ideal de ego. Diante de tamanha idealização, o resultado é a depressão, pois os ideais de ego, extremamente exigentes, dificilmente são alcançados. As principais características desse arranjo são o narcisismo exacerbado, com permanência de uma intensa imaturidade afetiva, e a angústia principal é a de perda do objeto (Bergeret, 2006).

Outros autores, a partir das indicações de quatro modelos clínicos basais do campo psicanalítico a partir da obra de Freud, também ressaltam a pertinência de pensar as psicopatologias contemporâneas a partir do modelo melancólico e de seus desenvolvimentos na tradição das relações de objeto (Pinheiro, 2002; Figueiredo, 2003; Mezan, 2014). Assim, é possível pensar em um encaminhamento consistente de discussão do narcisismo que aponta para o modelo da melancolia e para a elaboração da angústia pela perda do objeto como um fator central para a compreensão das demandas de sofrimento psíquico próprias da contemporaneidade, independente de uma caracterização nosográfica mais precisa ou específica em termos de concepções psicopatológicas dentro do campo psicanalítico. Nessa concepção, está contemplado o reconhecimento de que a relação de objeto narcísica está permeada pela problemática melancólica, em que o luto pela perda do objeto é o elemento em jogo e está marcada por identificações narcísicas. Além disso, entende-se que a relação com a instância ideal é propriamente da ordem de um ideal de ego narcísico, fruto da identificação com o desejo materno e não com a função paterna e a lei simbólica. Por conta disso, sua angústia não é exatamente a culpa moral, mas sim da ordem da dor de existir e do luto e, portanto, um sofrimento propriamente narcísico.

Essa caracterização geral, por sua vez, é bastante pertinente ao que foi apresentado no tópico anterior sobre o filme, indicando a necessidade de ir para além de um olhar de culpabilização moral, quer seja a partir do quadro de referência neurótico ou da perversão, para indicar a dimensão propriamente narcísica de sofrimento que está velada sob a conduta dos personagens. Portanto, não se trata da celebração das condutas sexuais impulsivas e compulsivas, nem do 
triunfo de saídas maníacas, mas da possibilidade de fratura e de expressão da dor narcísica. É nesse sentido que entendemos que o filme não diz respeito fundamentalmente à perversão ou à mania no âmbito das condutas e relações sexuais ou da atuação de uma culpa edípica em relação a uma sexualidade proibida e marcada pelo sadismo, mas às diversas formas de lidar com o desamparo frente à angústia pela perda do objeto na constituição do narcisismo.

Contudo, o que pouco se ressalta é que um dos qualificativos do sofrimento narcísico pode ser caracterizado propriamente como vergonha. Nesse sentido, é preciso apontar que o título "Vergonha" (Shame) ilustra o conflito central da temática que o filme aborda. Este título curto e simples parece mostrar que é sob o signo da vergonha que se qualifica a tonalidade afetiva de toda a história. Essa escolha é muito adequada e o olhar psicanalítico nos permite avançar em sua consideração. Isso porque no senso comum, poder-se-ia entender que a vergonha em jogo seja um mero qualificativo moral, que julga as condutas sexuais inadequadas e quase perversas do personagem principal. Ele seria então um "viciado" em sexo, que toma as pessoas como meros objetos e deveria buscar uma sexualidade normativa. No esteio dessa perspectiva, o filme deveria mostrar a redenção do sujeito saindo da posição transgressiva e submetendo-se à ordem moral, mas não é isso que se passa. Em primeiro lugar, porque ele não banaliza a questão mostrando posições extremas e ilusórias, mas também não adota uma postura moralista de julgamento e penalização do sujeito. Em segundo lugar, porque não se trata dessa vergonha da qual um "sem-vergonha" ou "promíscuo" carece. Essa vergonha de quem é pego no ato de transgressão da lei é apenas uma forma secundária da culpa diante da castração simbólica. A vergonha fundamental, que não é um derivado ou recoberta pela culpa, é de uma ordem mais narcísica.

A vergonha é um sentimento que gradualmente vem sendo mais estudado no meio psicanalítico. A literatura nacional recente já apresenta alguns trabalhos sobre o tema, em geral apontando a sua vinculação com o narcisismo e sua diferenciação do sentimento de culpa (Bilenky, 2014; Costa 2012; Mautner, 2003; Vertzman, 2011, 2014). Nessa perspectiva, entende-se que é um aspecto constitutivo fundamental da subjetividade e da regulação das relações sociais, mas que em sua dimensão traumática tende a provocar defesas intensas que levam à inibição do pensamento e ao encobrimento afetivo, de forma que se expressa em pouca disponibilidade e reserva dos pacientes (Bilenky, 2014). Costa (2012), em sua sistematização dessa problemática, enuncia que a vergonha se articula intimamente ao campo da melancolia e do narcisismo, como expressão afetiva privilegiada dessas dinâmicas. Do ponto de vista de sua caracterização descritiva, o autor afirma que o sentimento de vergonha pode ser concebido por meio de dois aspectos fenomênicos 
contraditórios: o medo da exposição ao outro e o medo de ser ignorado pelo outro. O sujeito deseja ser reconhecido como objeto de investimento do outro, teme, porém, não possuir os atributos que supostamente deveria ter. Surge então um paradoxo do conflito do envergonhado: não querer ser notado e nem querer deixar de ser visto. Do ponto de vista de caracterização metapsicológica e explicativa, o autor afirma que na montagem fantasística da vergonha estariam implícitos a depressão e o narcisismo. Na ideia da depressão o que se sublinha é a ausência de culpa. Essa depressão da vergonha está ligada ao sentimento de insuficiência diante do desejo imposto ao outro. O sujeito não se sente a altura do outro e se apropria então de marcas pessoais como justificativa dessa insuficiência. Por fim, o autor ressalta que "o monopólio da vida mental pelo emblema da vergonha (...) tem no corpo físico um teatro privilegiado para sua expressão" (Costa, 2012, p. 11).

Como se pode notar, a dinâmica da vergonha, a partir de uma matriz melancólica, caracteriza-se como um conflito organizado muito mais em relação ao ideal de ego narcísico, ou seja, corresponder ao desejo do outro e poder ser um com o outro, do que ao ideal de ego propriamente edípico, ou seja, respeitar o limite da castração e ter o poder de significar um objeto de desejo para um outro. 0 qualificativo dessa vergonha não é a culpabilidade, mas um sentimento de total onipotência ou de vazio que não é mediado por um sistema abstrato de símbolos. Ela é mais imediata, dual e confusional, afeita a oscilações entre condutas impulsivas e maníacas, além de sentimentos de vazio e impotência. Isso se expressa também na labilidade dos mecanismos de defesa e dos sintomas.

Essa caracterização coaduna bem com o que pudemos interpretar da pluralidade de mecanismos e sintomas em Brandon e Sissy, onde a culpa neurótica ensejando passagens ao ato ou isolamentos afetivos próximos da fobia parecem ser efeito de mecanismos mais próximos da problemática melancólica, em que a questão é o sadismo em relação ao objeto idealizado e seu retorno sobre o ego. $O$ que temos a acrescentar é que para além da dor de existir há também o aprisionamento do sujeito em um jogo narcísico de espelhos que se expressa fundamentalmente como vergonha. Essa angústia de perda de objeto e a vergonha diante do ideal de ego, promove um conflito entre a dependência e a autossuficiência que é o que caracteriza propriamente o que se costuma identificar como uma personalidade narcisista.

Costa (2012) encerra sua apresentação da vergonha como paradigmática do sofrimento narcísico apontando que a raiz do processo de envergonhamento estaria na questão materna sem a intenção de amor. O sujeito da vergonha seria reconhecido como sujeito único, mas sem qualidades. A representação imaginária 
solidificou-se em torno do vácuo de ideais de eu maternos. Recorrendo ao referencial winnicottiano, afirma que a mãe ambiente existiu, mas não surgiu espaço para mãe-objeto, formando-se assim uma inconsistência egoica e uma dificuldade do sujeito de se perceber e se sentir como suporte de narrativas positivas. Em outras palavras, haveria algo da ordem de uma falha da função materna na constituição do ego em que os aspectos verdadeiros do self deram lugar a respostas orientadas às demandas do ambiente, criando uma personalidade assentada no falso self. Essa resposta seria característica de personalidades limítrofes, marcadas pela labilidade de condutas defensivas e sintomáticas.

Assim, a hipótese de que a dinâmica narcísica entre o ego e o ideal de ego própria do modelo melancólico, embasada em defesas contra a angústia pela perda do objeto primário e cuja expressão privilegiada se dá por meio do registro do corpo e da ação e marcada pelo emblema afetivo da vergonha e não da culpa, ganha respaldo. Brandon e Sissy parecem mostrar durante todo o filme a vergonha de não ser e de não apresentar uma imagem suficientemente boa aos olhos do outro internalizado como ideal. O sentimento de insuficiência de Brandon ultrapassa todas as suas qualidades e, a partir do momento em que sua irmã descobre seu lado oculto, ele, em uma tentativa de expelir de si suas angústias, realiza uma saída extrema de eliminar seus objetos maus que ameaçavam os seus bons objetos internalizados e idealizados. Mesmo se enquadrando em todas as normas da sociedade isso nunca será suficiente para se orgulhar de alguma qualidade ou acabar com suas angústias de perda de objeto, dado o seu exacerbado ideal de ego, que é muito inflado e idealizado, e por isso mesmo, fatal, visto que é humanamente impossível alcançar essa imagem que ele deseja para si. Da mesma forma, Sissy sofre da impossibilidade de alcançar esse ideal de mulher que projeta, posicionando-se de forma infantilizada, vitimizada e passiva no seu desejo sexual e nos seus vínculos amorosos. Ambos sofrem da fragilidade emocional característica dos sofrimentos narcísicos próprios do mal-estar na contemporaneidade.

\section{Considerações Finais}

Diante do exposto, pode-se concluir que o filme ilustra, por meio da análise de seus protagonistas, com destaque para Brandon, independente de uma preocupação nosográfica ou psicopatológica específica, saídas para o desamparo e o desejo muito próprias do mal-estar contemporâneo. Pretendemos demonstrar como o filme é emblemático das vicissitudes dos modos de subjetivação contemporâneos, em que a relação com as instâncias ideais se caracteriza muito mais pela mediação do ideal de ego narcísico, cujo 
teor afetivo é da ordem da vergonha. Por conta disso, permite concluir que o título do filme é bastante adequado às questões psicodinâmicas que se apresentam em seu enredo e também ilustrativo da angústia depressiva e do vazio existencial que estão na base do mal-estar na cultura do narcisismo própria da atualidade. Como apontado na introdução, um trabalho de psicanálise aplicada tem sérias limitações quando pretende ser um exercício de interpretação psicodinâmica e classificação de estrutura psicopatológica de personagens fictícios, mesmo que com pretensões meramente ilustrativas ou didáticas. Nossa intenção, contudo, não foi enveredar por esse caminho, mas fazer um exercício mais ensaístico a partir de algumas indicações pertinentes e paradigmáticas encontradas na obra cinematográfica objeto de análise como forma de problematizar os modos de subjetivação na contemporaneidade, enfatizando algumas perspectivas conceituais que têm ganhado destaque na literatura.

\section{Referências}

Argentieri, S. (2012). Distúrbio sexual é abordado em Shame de Steve McQueen. Viver Mente e Cérebro, novembro 2012. São Paulo: Editora Segmento. Disponível em: http://www2.uol.com.br/vivermente/noticias/disturbio_sexual_ e_abordado_em_shame_de_steve_mcqueen.html Acesso em: 01 de junho de 2014.

Bauman, Z. (2009). Amor líquido: sobre a fragilidade dos laços humanos. Rio de Janeiro: Jorge Zahar.

Bergeret, J. (2006). Psicopatologia: teoria e clínica. 9. ed. Porto Alegre: Artmed.

Bergeret, J. (1974). Personalidade normal e patológica. Porto Alegre: Artes Médicas.

Bilenky, M. K. (2014). Vergonha: sofrimento e dignidade. Ide, 37(58): 133-145.

Birman, J. (2001). Mal-estar na atualidade: a psicanálise e as novas formas de subjetivação. 4. ed. Rio de Janeiro: Civilização Brasileira.

Birman, J. (2006). Arquivos do mal-estar e da resistência. Rio de Janeiro: Civilização Brasileira.

Birman, J. (2012). O sujeito na contemporaneidade. Rio de Janeiro: Civilização brasileira.

Campos, E. B. V. (2013). Considerações sobre a morte e o luto em psicanálise. Revista de psicologia da UNESP, 12(1): 13-24.

Costa, J. F. (2005). O vestígio e a aura: corpo e consumismo na moral do espetáculo. Rio de Janeiro: Garamond. 
Costa, J. F. (2012). Os sobrenomes da vergonha. In J. Vertzman, R. Herzog, T. Pinheiro, F. P. Ferreira (Orgs.) Sofrimentos narcísicos (pp. 9-16). Rio de Janeiro: Cia do Freud.

Delouya, D. (2001). Depressão. São Paulo: Casa do Psicólogo.

Dor, J. (1991). O pai e sua função em psicanálise. Rio de Janeiro: Jorge Zahar.

Freud, S. (1996a). Recordar, repetir e elaborar (Novas recomendações sobre a técnica da psicanálise II). In Edição standard brasileira das obras completas de Sigmund Freud, v. XII (pp. 159-172). Rio de Janeiro: Imago. (Trabalho original publicado em 1914a).

Freud, S. (1996b). Narcisismo: uma introdução. In S. Freud Edição standard brasileira das obras completas de Sigmund Freud, v. XIV (pp. 89-122). Rio de Janeiro: Imago. (Trabalho original publicado em 1914b).

Freud, S. (1996c). Luto e melancolia. In S. Freud Edição standard brasileira das obras completas de Sigmund Freud, v. XIV (pp. 243-263). Rio de Janeiro: Imago. (Trabalho original publicado em 1917).

Freud, S. (1996d). Neurose e psicose. In S. Freud Edição standard brasileira das obras psicológicas completas de Sigmund Freud, v. XIX (pp. 163-171). Rio de Janeiro: Imago. (Trabalho original publicado em 1924).

Freud, S. (1996e). Fetichismo. In S. Freud Edição standard brasileira das obras completas de Sigmund Freud, v. XXI (pp. 179-188). Rio de Janeiro: Imago. (Trabalho original publicado em 1927).

Fuks, L. B. (2003). Narcisismo e vínculos na atualidade. Percurso, ano XVI, 30, 25-30. Disponível em: http://revistapercurso.uol.com.br/pdfs/p30_texto03.pdf Acesso em: 01 de junho de 2014.

Fuks, L. B. (2010). Narcisismos e vínculos: ensaios reunidos. São Paulo: Casa do Psicólogo.

Figueiredo, L. C. (2003). Psicanálise: elementos para a clínica contemporânea. São Paulo: Escuta.

Green, A. (1988). Narcisismo de vida - narcisismo de morte. São Paulo: Escuta.

Klein, M. (1991). Notas sobre alguns mecanismos esquizoides. In M. Klein Inveja, gratidão e outros trabalhos: obras completas de Melanie Klein, v. 3 (pp. 17-43). Rio de Janeiro: Imago. (Trabalho original publicado em 1946).

Klein, M. (1996). O luto e sua relação com os estados maníacodepressivos. In M. Klein Amor, culpa e reparação: obras completas de Melanie Klein, v. 1 (pp. 385-412). Rio de Janeiro: Imago. (Trabalho original publicado em 1940).

Kernberg, O. F. (1995). Transtornos graves de personalidade. Porto Alegre: Artes Médicas. 
Kobori, E. T. (2013). Algumas considerações sobre o termo psicanálise aplicada e o método psicanalítico na análise da cultura. Revista de psicologia da UNESP, 12(2): 73-81.

Lacan, J. (1998). O estádio do espelho como formador da função do eu tal como nos revela a experiência psicanalítica. In: J. Lacan Escritos (pp. 96-103). Rio de Janeiro: Jorge Zahar Editora. (Trabalho original publicado em 1949).

Lacan, J. (1954/1986). Os dois narcisismos. In J. Lacan. Os escritos técnicos de Freud. O Seminário - Livro 1 (pp. 140-151). Rio de Janeiro: Jorge Zahar Editora. (Seminário ministrado em 19531954).

Laplanche, J., Pontalis J.-B. (1998). Vocabulário da psicanálise. 4. ed. São Paulo: Martins Fontes.

Mautner, A. V. (2003). Vergonha. Psicologia USP, 14(2): 225-229.

McQueen, S. (2011). Shame. Filme. 101 minutos. Roteiro Abi Morgan e Steve McQueen. Inglaterra.

Mezan, R. (2014). O tronco e os ramos: estudos sobre história da psicanálise. São Paulo: Companhia das Letras.

Pinheiro, T. (2002). Escuta analítica e novas demandas clínicas: sobre a melancolia na contemporaneidade. Psychê, 9, 167-176.

Rosa, M. D. (2004). A pesquisa psicanalítica dos fenômenos sociais e políticos: metodologia e fundamentação teórica. Revista Malestar e Subjetividade, IV(2): 329-348. Disponível em: http://pepsic.bvsalud.org/pdf/malestar/v4n2/08.pdf Acesso em: 01 de junho de 2014.

Verztman, J. S. (2014). Embaraço, humilhação e transparência psíquica: o tímido e sua dependência do olhar. Ágora: Estudos em Teoria Psicanalítica, 17(spe), 127-140.

Verztman, J. S. (2011). Freud e a vergonha. Cadernos de Psicanálise, $27,73-99$.

\section{Endereço para correspondência \\ Maysa Maria Napolitano Machado}

Faculdade de Ciências de Bauru - UNESP

Departamento de Psicologia

Av. Luiz Edmundo Carrijo Coube, 14-01, Vargem Limpa, CEP 17033-360, Bauru SP, Brasil

Endereço eletrônico: maysa.m_@hotmail.com

Victória de Freitas Branco

Faculdade de Ciências de Bauru - UNESP

Departamento de Psicologia

Av. Luiz Edmundo Carrijo Coube, 14-01, Vargem Limpa, CEP 17033-360, Bauru SP, Brasil

Endereço eletrônico: vickfbranco@hotmail.com

Maíra Bittar Galdi

Faculdade de Ciências de Bauru - UNESP

Departamento de Psicologia 
Av. Luiz Edmundo Carrijo Coube, 14-01, Vargem Limpa, CEP 17033-360, Bauru SP, Brasil

Endereço eletrônico: mah.bg@hotmail.com

Érico Bruno Viana Campos

Faculdade de Ciências de Bauru - UNESP

Departamento de Psicologia

Av. Luiz Edmundo Carrijo Coube, 14-01, Vargem Limpa, CEP 17033-360, Bauru SP, Brasil

Endereço eletrônico: ebcampos@fc.unesp.br

Recebido em: 24/08/2015

Reformulado em: 17/05/2016

Aceito para: 25/05/2016

\section{Notas}

* Graduanda em Psicologia e bolsista do Projeto de Extensão "Psicopatologia Psicanalítica - Casos Clínicos e Cineclubes". Universidade Estadual Paulista "Júlio de Mesquita Filho" - UNESP - Campus de Bauru.

** Graduanda em Psicologia e bolsista do Projeto de Extensão "Psicopatologia Psicanalítica - Casos Clínicos e Cineclubes". Universidade Estadual Paulista "Júlio de Mesquita Filho" - UNESP - Campus de Bauru

*** Graduanda em Psicologia e bolsista do Projeto de Extensão "Psicopatologia Psicanalítica - Casos Clínicos e Cineclubes". Universidade Estadual Paulista "Júlio de Mesquita Filho" - UNESP - Campus de Bauru

**** Psicólogo, mestre e doutor em Psicologia. Coordenador do Projeto de Extensão "Psicopatologia Psicanalítica - Casos Clínicos e Cineclubes". Professor do Departamento de Psicologia da Universidade Estadual Paulista "Júlio de Mesquita Filho" - UNESP - Campus de Bauru. 